\title{
Optimal Operation for Green Supply Chain Considering Demand Information, Collection Incentive and Quality of Recycling Parts
}

\author{
Takeshi Watanabe, Etsuko Kusukawa* \\ Graduate School of Engineering, Osaka Prefecture University, Osaka, Japan
}

(Received: March 2, 2014 / Revised: May 2, 2014 / Accepted: May 6, 2014)

\begin{abstract}
This study proposes an optimal operational policy for a green supply chain (GSC) where a retailer pays an incentive for collection of used products from customers and determines the optimal order quantity of a single product under uncertainty in product demand. A manufacturer produces the optimal order quantity of product using recyclable parts with acceptable quality levels and covers a part of the retailer's incentive from the recycled parts. Here, two scenarios for the product demand are assumed as: the distribution of product demand is known, and only both mean and variance are known. This paper develops mathematical models to find how order quantity, collection incentive of used products and lower limit of quality level for recycling affect the expected profits of each member and the whole supply chain under both a decentralized GSC (DGSC) and an integrated GSC (IGSC). The analysis numerically compares the results under DGSC with those under IGSC for each scenario of product demand. Also, the effect of the quality of the recyclable parts on the optimal decisions is shown. Moreover, supply chain coordination to shift the optimal decisions of IGSC is discussed based on: I) profit ratio, II) Nash bargaining solution, and III) Combination of (I) and (II).

Keywords: Green Supply Chain, Demand Information, Distribution-Free Approach, Collection Incentive, Uncertainty Quality of Recyclable Parts, Game Theory

* Corresponding Author, E-mail: kusukawa@eis.osakafu-u.ac.jp
\end{abstract}

\section{INTRODUCTION}

Due to the recent rise of social concern about the environment problem, the concept of a new supply chain management has been important in optimally controlling a supply chain including traditional forward chains/logistics and reverse chains/logistics. The traditional forward chains/logistics include the flows from procurement of new materials through production of new products to selling them. The reverse chains/logistics include the flows from collection of used products through recycling parts from the used products to reuse the recycled parts (Aras et al., 2004; Behret and Korugan, 2009; Ferguson et al., 2009; Fleischman et al., 1997; Guide and
Wassenhove, 2001; Inderfurth, 2005; Konstantaras et al., 2010; Mukhopadhyay and Ma, 2009; Nenes et al., 2010; Pokharel and Liang, 2012; Teunter and Flapper, 2011; Wei et al., 2011; Wu, 2012).

Also, a supply chain including the forward chains and the reverse chains has been called a closed-supply chain, reverse supply chain or a green supply chain (GSC) (Bakal and Akcali, 2006; Fleischman et al., 1997; Guide et al., 2003; Inderfurth, 2005; Kaya, 2010; Lee et al., 2011; Shi et al., 2010, 2011; Tagaras and Zikopoulos, 2008; Thierry et al., 1995; Van Wassenhove and Zikopoulos, 2010; Wei et al., 2012; Yan and Sun, 2012; Zikopoulos and Tagaras, 2007, 2008). In this study, the supply chain that has the forward chains and the reverse 
chains is called a GSC. The manufacturing to reuse recycled parts is called the remanufacturing. It is necessary to take some measures and policies in order to promote 3R activities (Reuse-Recycle-Reduce) in the GSC.

Several previous papers have dealt with the optimal operations for GSC, and the uncertainty in remanufacturing has been attracting more attention in recent papers.

The incorporation of the uncertainty in demands of products/parts and collection quantity of used products into GSC have been discussed by Inderfurth (2005), Lee et al. (2011), Mukhopadhyay and Ma (2009), Shi et al. (2010, 2011), and Wei et al. (2011).

The incorporation of the price-sensitivity in collection quantity of used products and demands of products/ parts into the optimal tactical production planning GSC have been discussed by Bakal and Akcali (2006), Pokharel and Liang (2012), Shi et al. (2010), Teunter and Flapper (2011), Wei et al. (2012), and Yan and Sun (2012).

Also, the effects of inspection and sorting of used products on the optimal tactical production planning in GSC have been discussed by Aras et al. (2004), Behret and Korugan (2009), Ferguson et al. (2009), Guide et al. (2003), Konstantaras et al. (2010), Nenes et al. (2010), Tagaras and Zikopoulos (2008), Van Wassenhove and Zikopoulos (2010), and Zikopoulos and Tagaras (2007, 2008).

In dealing with the GSC, it is necessary to consider a variety of qualities of used products collected from the market. Some authors have discussed the optimal tactical production planning by incorporating uncertainty in the quality of used products into the GSC. Aras et al. (2004) investigated the issue of the stochastic nature of product returns and found conditions under which quality-based categorization was most cost effective. Zikopoulos and Tagaras (2007) investigated how the profitability of reuse activities was affected by uncertainty regarding the quality of returned products in two collection sites and determined the unique optimal solution (procurement and production quantities). In Guide et al. (2003) and Ferguson et al. (2009), returned products were assumed to have $\mathrm{N}$ quality categories, and the procurement prices and the remanufacturing costs were different based on the corresponding quality level. Behret and Korugan (2009) discussed a remanufacturing stage with uncertainties in the quality of remanufacturing products, return rates, and return times of returned products. After returned products were classified by considering quality uncertainties, remanufacturing processing times, material recovery rates, the remanufacturing costs, and disposal costs were determined by using the ARENA simulation program. Mukhopadhyay and Ma (2009) discussed a GSC consisting of a retailer who sold a single product and a manufacturer who collected used products from the market, remanufactured parts from the used products and then produced products. They assumed two situations for the remanufacturing ratio between reuse parts and used products: a constant situation and an uncertain situation. Under each situation, they proposed the optimal production strategy for the procurement quantity of used products, the remanufacturing quantity of parts from used products and the production quantity of new parts from new materials. Nenes et al. (2010) observed that both quality and quantity of returns (used products) were unfortunately highly stochastic, and investigated the optimal policies for ordering of new products and remanufacturing of products so as to maximize the companies' performance, such as minimizing their expected cost or maximizing their expected profit. Teunter and Flapper (2011) discussed how quality of cores (i.e., products supplied for remanufacturing) could vary significantly, affecting the cost of remanufacturing, and derived the optimal policies regarding acquisition and remanufacturing for both deterministic and uncertain demand.

Kaya (2010) discussed a GSC consisting of a retailer who collected used products from customers and sold a single product and a manufacturer who remanufactures parts from the used products and produced the products. They proposed the optimal decisions for collection incentive of used products and production quantities of both remanufacturing parts and new parts.

Also, it is necessary to determine the optimal operations to establish a GSC to obtain its profitability. In a decentralized GSC, all members in the GSC determine the optimal operations so as to maximize their profits. As one of the optimal decision-making approaches under a decentralized GSC, the Stackelberg game has been adopted in several previous papers. In the Stackelberg game, there is a single leader of the decision-making and a single (multiple) follower(s) of the decision-making of the leader. The leader of the decision-making determines the optimal strategy so as to maximize the leader's (expected) profit. The follower(s) of the decision-making determine(s) the optimal strategy so as to maximize the follower(s)'s (expected) profit under the optimal strategy determined by the leader of the decision-making (Aust and Buscher, 2012; Berr, 2011; Cachon and Netessine, 2004; Cai et al., 2009; Esmaeili and Zeephongsekul, 2010; Hu et al., 2011; Lee et al., 2011; Leng and Parlar, 2009; Liu et al., 2012; Mukhopadhyay et al., 2011; Xu et al., 2012; Yan and Sun, 2012).

Also, in a supply chain management, the optimal decisions under an integrated supply chain maximizing the whole supply chain's expected profit can bring the more expected profit to the whole supply chain than those under a decentralized supply chain maximizing the expected profit of each member in a supply chain. So, from the aspect of the total optimization in supply chain management, it is preferable for all members in supply chain to shift the optimal decisions under the integrated supply chain. In this case, it is the absolute requirement for all members under the integrated supply chain to obtain the more expected profits than those under the decentralized supply chain. In order to achieve the increases in profits of all members under the integrated supply chain, a variety of supply chain coordination ap- 
proaches between all members have been discussed by Cachon and Netessine (2004), Du et al. (2011), Kaya (2010), Tsay et al. (1999), Wei et al. (2012), Wu (2012), Yan and Sun (2012), and Yano and Gilbert (2004).

The incorporation of the game theory into not only the optimal pricing strategies, but also the supply chain coordination in a GSC have been discussed by Kaya (2010), Wei et al. (2012), Wu (2012), Yan and Sun (2012), and Du et al. (2011).

From the previous papers regarding GSC, product recovery, recycling, remanufacturing and reverse logistics, the lower level of quality levels of used products were not considered for the optimal decision for the remanufacturing ratio. Also, in the previous papers above, the relation between a collection incentive of used products and the collection quantity of used products was not described clearly. In addition, the cost for recycling used products has not been considered as profits in GSC in the above previous papers.

Regarding these discussions mentioned above, Watanabe et al. (2013) discussed the following optimal production policy for two types of GSCs: optimal decisions for the product quantity, the unit collection incentive of used products and the lower limit of quality level for recycling of used products under both the decentralized GSC (DGSC) and the integrated GSC (IGSC).

In GSCs mentioned above, a demand of a single product assumes a random variable, and the probability distribution of the demand is known. This implies that it is possible to obtain the full information of the product demand. In a real situation for the GSC, it may be possible to get the limited information, such as mean and variance of the product demand. Under such a situation, Gallego and Moon (1993), Moon and Gallego (1994), Moon and Choi (1995), Alfares and Elmorra (2005) discussed the distribution-free newsboy problem for a single product in a single period.

This paper focuses on the optimal operation for a GSC to encourage to collect and recycle a single of used products, such as consumer electronics (mobile phone, personal computer), semiconductor and electronic component (Daniel et al., 2000; Guide and Van Wassenhove, 2001; Guide et al., 2003; Ferguson et al., 2009) under the uncertainties in product demand and quality of used products collected from customers.

When the GSC is operated to collect used products from customers, recycle them and sell a single product reusing the recycled parts under the uncertainties in product demand and quality of used products collected from customers, practitioners and academics may have the following questions to discuss the operation of a GSC: 1) how much a retailer should pay for an incentive to encourage to collect used product from customers, 2) how the quality of recyclable parts after disassembly of used products affect the recycling activity of a manufacturer and the profit, 3) how a retailer determines the optimal order quantity of the product under the uncertainty in demand of product. This study tries to answer the above questions to operate a GSC optimally and profitably, and to make the following contributions for academic researchers and real-world policymakers regarding operations in a GSC:

- Presentation of theoretical analysis to encourage the collection and the recycling of used products by incorporating a collection incentive of used products into a GSC.

- Presentation of theoretical analysis to evaluate the profitability obtained from the optimal operations for a product quantity of a single product, a collection incentive of used products and a lower limit of used product under DGSC and IGSC.

- Presentation of theoretical analysis to incorporate the uncertainty in demand of a single of products under the following scenarios: 1) the distribution of product demand is known, 2) the product demand has unknown distribution with known mean and known variance into calculation of the expected profit in a GSC.

- Presentation of theoretical analysis to provide the optimal decision approach under a situation where the product demand has unknown distribution with known mean and known variance.

- Presentation of theoretical analysis to evaluate how quality of distribution of recyclable parts after disassembly of used product affect the optimal operational for order quantity, collection incentive of used products and lower limit of quality level for recycling and the expected profit of the manufacturer.

- Presentation of theoretical analysis to provide how incorporation of profit sharing approach into IGSC can not only promote the more aggressive eco-activity among all members in the GSC, but also shift to the decision-making under IGSC from that under DGSC.

Concretely, this study proposes an optimal production policy for a GSC with material flows from collection of used products to reuse of recycled parts in production of products. In the GSC, a retailer pays an incentive for collection of used products from customers and hands them over to a manufacturer. In this case, the retailer places an order for an order quantity of the products to the manufacturer, considering the product demand uncertainty. The manufacturer disassembles the used products, and then classifies the recyclable parts into quality levels by the result of the inspection of the used products. The manufacturer remanufactures products using recyclable parts with acceptable quality levels and pays the compensation a part of the retailer's incentive for collection of used products based on the quantity of the recycled parts to the retailer.

Here, the uncertainty in demand of a single product which a retailer faces to sell the product in a market are assumed as the following scenarios: 1) the distribution of product demand is known, 2) the product demand has unknown distribution with known mean and known variance. 
For each situation, this paper develops two types of mathematical models and conducts the theoretical analysis in order to find how order quantity, collection incentive of used products and lower limit of quality level for recycling of used products affect the expected profits of each member and the whole supply chain (SC) under both DGSC and IGSC. Specifically, two types of optimal decisions are proposed for product quantity, collection incentive of used products and lower limit of quality level for recycling in GSC. One is under DGSC whose objective is to maximize the expected profit of each member based on optimal decision approach of the Stackelberg game. The other is under IGSC whose objective is to maximize the whole SC's expected profit.

The analysis numerically investigates how the following factors: i) available distribution information of product demand, ii) the quality of the recyclable parts after disassembly of used products affect the optimal operation and the expected profits a retailer, a manufacturer and the whole SC under DGSC and IGSC. Additionally, the results of optimal operation under DGSC is compared with that under IGSC under above factors (i) and (ii). Moreover, as supply chain coordination, the effects of three profit sharing approaches on each members' profit are investigated under IGSC: I) Adoption of profit ratios between members, II) Adoption of Nash bargaining solution (Nagarajan and Sosic, 2008; Du et al., 2011), III) Adoption of the combination of (I) and (II).

The contribution of this paper is to provide the following managerial insights from the outcomes obtained from the theoretical research and the numerical analysis to academic researchers and real-world policymakers regarding operations in a GSC:

- The optimal order quantity in the scenario 2 where the product demand has unknown distribution with known mean and known variance is determined as a lower value than the scenario 1 where the distribution of product demand is known. This is due to the situation where the optimal decision in the scenario 2 is made under the worst situation where a retailer obtains the lowest expected profit.

- It is possible to guarantee to bring more profits to all members (a retailer and a manufacturer) in a GSC by taking the more aggressive eco-activity where not only a retailer pays incentive to customers in order to collect the more used products from customers, but also a manufacturer compensate some parts of incentive the retailer paid. Therefore, incorporation of the optimal collection incentive into a GSC can encourage both activities of the collection and the recycling of used products, guaranteeing the expected profits of a retailer, a manufacturer and the whole $\mathrm{SC}$ in the GSC.

- It is profitable to determine optimally the lower level of quality of recyclable parts after disassembly of the used products when the quality of recyclable parts is distributed several quality level.
- The optimal lower level of quality of recyclable parts under IGSC can be determined as a lower value than that under DGSC. Also, the optimal collection incentive under IGSC can be determined as a higher value than that under DGSC. Therefore, the optimal decisions under IGSC can encourage the more aggressive eco-activity among a retailer, a manufacturer and the whole SC in GSC.

- From the aspect of profit, incorporation of profit sharing approach into IGSC can not only promote the more aggressive eco-activity among all members in a GSC, but also shift to the decision-making under IGSC, guaranteeing the more expected profits of all members and the whole SC in a GSC.

The rest of our paper is organized as follows: in Section 2, notation used in our model is defined. In Section 3, operational flows of a GSC and the model assumptions are described. Section 4 formulates the expected profits in GSC. Section 5 proposes the optimal decisionmaking under DGSC and IGSC. Section 6 discusses incorporation of profit sharing approach into IGSC as supply chain coordination. Section 7 shows the results of numerical examples to illustrate managerial insights for the optimal operation of the GSC proposed in our paper. In Section 8, conclusions, managerial insights and future researches for this paper are summarized.

\section{NOTATION}

The following notations are used to formulate a GSC addressed in this paper.

\section{General notations}

$Q \quad$ : order quantity of product, referred to order quantity

$t \quad$ : collection incentive per used product (purchasing cost), referred to collection incentive

$u$ : lower limit of quality level to remanufacture recyclable parts after disassembly of used products, referred to lower limit of quality level $(0 \leq u \leq 1)$

$A(t)$ : collection quantity of product for collection incentive $t$

$R(t)$ : compensation per used product paid to a retailer from a manufacturer for the amount of used products which are remanufactured

$c_{a} \quad$ : disassembly and inspection cost per used product

$\ell \quad$ : quality level of recyclable parts $(0 \leq \ell \leq 1)$

$g(\ell)$ : probability density function of quality level $\ell$

$c_{r}(\ell)$ : remanufacturing cost per a recyclable part in the case of quality level $\ell$

$c_{d} \quad$ : disposal cost per un-reused part

$c_{n}$ : procurement cost per new part

$c_{m} \quad$ : production cost per product

$m_{a}$ : margin obtained from wholesale per product

$w$ : wholesale price of product, referred to unit wholesale price 
$p \quad:$ sales price per product, referred to unit sales price

$t_{U} \quad$ : upper limit of collection incentive $t$

$s \quad$ : shortage penalty cost per product of which demand is unsatisfied

$h_{r} \quad$ : inventory holding cost per unsold products

$x$ : demand of product in a market

$f(x)$ : probability density function of demand $x$

\section{Notations for a DGSC}

$Q_{D}^{*} \quad$ : optimal order quantity under DGSC

$t_{D}^{*} \quad$ : optimal collection incentive under DGSC

$u_{D}(t)$ : provisional lower limit of quality level determined for a given collection incentive $t$ under DGSC

$u_{D}^{*} \quad$ : optimal lower limit of quality level under DGSC

Notations for an IGSC

$Q_{C}^{*} \quad$ : optimal order quantity under IGSC

$t_{C}^{*} \quad$ : optimal collection incentive under IGSC

$u_{C}^{*} \quad$ : optimal lower limit of quality level under IGSC

\section{MODEL DESCRIPTIONS}

\subsection{Operational Flows of a GSC}

(1) A GSC consisting of a retailer and a manufacturer is considered. Also, it is assumed that a single product such as consumer electronics (mobile phone, personal computer), semiconductor and electronic component is produced and is sold in a market.

(2) A retailer pays the unit collection incentives $t$ to collect used products from a market and delivers the collection quantity $A(t)$ of the used products with the unit cost $c_{t}$ to the manufacturer.

(3) A manufacturer disassembles the used products, inspects all the recyclable parts with the unit $\operatorname{cost} c_{a}$. After the disassembly, the manufacturer classifies the recyclable parts into the quality level $\ell(0 \leq \ell \leq 1)$. The manufacture determines optimally the lower limit of quality level $u(0 \leq u \leq 1)$ for the recyclable parts. The manufacturer remanufactures all the recyclable parts with quality level $\ell$ more than the lower limit of quality level $u$. The manufacturer disposes all the recyclable parts with lower quality level than $u$ with the unit cost $c_{d}$.

(4) The manufacturer pays the compensation to the retailer for the cooperation to collection of the used products. Concretely, the manufacture pays the compensation $R(t)$ to the retailer who paid the unit collection incentive $t$ to collect the quantity $A(t)$ of the used products.

(5) The retailer determines optimally the unit collection incentive $t$ and the order quantity $Q$ of the product under the uncertainty in product demand so as to maximize the retailer's expected profit. The retailer places an order of the quantity $Q$ of a single product with the manufacturer.
(6) The manufacturer produces the same quantity $Q$ of the product ordered from the retailer with the unit $\operatorname{cost} c_{m}$, and sells the product to retailer at the unit wholesale price $w$.

(7) The manufacturer produces the required quantity of new parts with the unit $\cos t c_{n}$ if the quantity of the recycled parts is unsatisfied with the required quantity of parts for the order quantity $Q$.

(8) The retailer sells the product in a market with the unit sales price $p$ during a single period. The retailer incurs the unit inventory holding $h_{r}$ of the unsold products, while the retailer incurs the unit shortage penalty cost $s$ of the unsatisfied product demand.

\subsection{Model Assumptions}

(1) In the scenario $1(i=1)$ for the product demand, the demand $x$ follows a probabilistic distribution and the probability density function (PDF) of $x, f(x)$, is known. In the scenario $2(i=2)$, the product demand has unknown PDF with known mean $\mu$ and known variance $\sigma^{2}$ for the demand $x$. Here, $\mu>0, \sigma>0$ and $\sigma^{2}>0$.

(2) A single recyclable part is extracted from the unit of used products. The manufacturer remanufactures products using a single type of recyclable parts with acceptable quality levels.

(3) Regarding collecting the used products, a retailer pays the unit collection incentive $t$ to collect the used products from a market. Here, the collection quantity of the used products $A(t)$ varies according to the unit collection incentive $t$. In general, the higher the unit collection incentive $t$ is, the more a retailer can collect the used products from a market, where the unit collection incentive $t$ has the upper limit $t_{U}\left(0 \leq t \leq t_{U}<p\right)$. The manufacturer pays the compensation to cooperation of collecting the used products to the retailer. Concretely, the manufacturer pays the compensation $R(t)$ to the retailer who paid the unit collection incentive $t$ according to the quantity of the recycled parts from the used products. Here, the collection quantity $A(t)$ is not enough to satisfy the expected demand of product even if retailer pays the upper limit $t_{U}$ of $t$.

(4) The unit wholesale price $w$ is calculated from the unit procurement $\operatorname{cost} c_{n}$ of new parts, the unit production cost $c_{m}$ of product and the unit margin $m_{a}$ obtained from wholesales per product.

(5) The variability of quality level $\ell$ of the recyclable parts is modeled as a probabilistic distribution with the PDF $g(\ell)$.

(6) The unit remanufacturing $\operatorname{cost} c_{r}(\ell)$ to a recycled part from a recyclable part with $\ell$ varies as to the quality level $\ell(0 \leq \ell \leq 1)$. The lower the quality level $\ell$ is, the higher the unit remanufactured cost $c_{r}(\ell)$ is. Here, $\ell=0$ indicates the worst quality level of the 
recyclable parts, meanwhile $\ell=1$ indicates the best quality level of the recyclable products. Thus, $c_{r}(\ell)$ is a monotone decreasing function in terms of quality level $\ell$. Note that each quality of the recycled parts produced from recyclable parts is as good as that of new parts produced from new materials.

\section{EXPECTED PROFITS IN GSC}

First, the retailer's expected profit in scenario $1(i=1)$ of the product demand is discussed. From 2, the retailer's profit consists of the collection cost and the delivery cost of the used products, the procurement cost of product, the compensation revenue, the product sales, the inventory holding cost of the unsold products and the shortage penalty cost for unsatisfied product demand in a market. The retailer's expected profit in $i=1$ for the order quantity $Q$, the unit collection incentive $t$ and the lower limit of quality level $u, E^{1}\left[\pi_{R}(Q, t, u)\right]$, is formulated as

$$
\begin{aligned}
E^{1} & {\left[\pi_{R}(Q, t, u)\right]=-t A(t)-c_{t} A(t) } \\
& -w Q+R(t) \int_{u}^{1} g(\ell) A(t) d \ell \\
& +\left\{p \int_{0}^{Q} x f(x) d x+p Q \int_{Q}^{\infty} f(x) d x\right\} \\
& -h_{r} \int_{0}^{Q}(Q-x) f(x) d x \\
& -s \int_{Q}^{\infty}(x-Q) f(x) d x .
\end{aligned}
$$

In Eq. (1), the first term is the collection cost of the used products, the second term is the delivery cost of the used products, the third term is the procurement cost of product, the fourth term is the expected compensation revenue from a manufacturer, the fifth term is the expected product sales of product, the sixth term is the expected inventory holding cost of the unsold products the final term is the expected shortage penalty cost for unsatisfied product demand in a market.

The manufacturer's profit consists of the product wholesales, the disassembly and the inspection costs of the used products, the remanufacturing cost of recyclable parts after disassembly of the used products, the compensation cost to a retailer, the disposal cost of unrecycled parts, the procurement cost of new parts and the production cost of product. The manufacturer's expected profit for $Q, t$ and $u, E\left[\pi_{M}(u, t, Q)\right]$, is formulated as

$$
\begin{aligned}
E & {\left[\pi_{M}(Q, t, u)\right]=w Q-c_{a} A(t)-A(t) \int_{u}^{1} c_{r}(\ell) g(\ell) d \ell } \\
& -R(t) \int_{u}^{1} g(\ell) A(t) d \ell-c_{d} A(t) \int_{0}^{u} g(\ell) d \ell \\
& -c_{n}\left\{Q-A(t) \int_{u}^{1} g(\ell) d \ell\right\}-c_{m} Q
\end{aligned}
$$

In Eq. (2), the first term is the product wholesales, the second term is the disassembly and the inspection costs of the used products, the third term is the remanufacturing cost of recyclable parts after disassembly of the used products, the fourth term is the compensation cost to a retailer, the fifth term is the disposal cost of unrecycled parts, the sixth term is the procurement cost of new parts, and the final term is the production cost of product. Therefore, it can be seen from Eq. (2) that the manufacturer's expected profit is unaffected by any scenario of the product demand.

The whole SC's profit is calculated from the sum of the retailer's profit and the manufacturer's profit. In this case, the whole SC's profit consists of the collection cost and the delivery cost of the used products, the disassembly and the inspection costs of the used products, the remanufacturing cost of recyclable parts after disassembly of the used products, the disposal cost of un-recycled parts, the procurement cost of new parts and the production cost of product, the product sales, the inventory holding cost of the unsold products and the shortage penalty cost for unsatisfied product demand in a market. Therefore, the whole SC's expected profit in $i=1$ for $Q$, $t$ and $u, E^{1}\left[\pi_{S}(u, t, Q)\right]$, is obtained as the sum of both members' expected profits in Eqs. (1) and (2), corresponding to

$$
\begin{aligned}
& E^{1}\left[\pi_{S}(Q, t, u)\right]=E^{1}\left[\pi_{R}(Q, t, u)\right]+E\left[\pi_{M}(Q, t, u)\right] \\
& \quad=-t A(t)-c_{t} A(t)-c_{a} A(t) \\
& \quad-A(t) \int_{u}^{1} c_{r}(\ell) g(\ell) d \ell-c_{d} A(t) \int_{0}^{u} g(\ell) d \ell \\
& \quad-c_{n}\left\{Q-A(t) \int_{u}^{1} g(\ell) d \ell\right\}-c_{m} Q \\
& \quad+p \int_{0}^{Q} x f(x) d x+p Q \int_{Q}^{\infty} f(x) d x \\
& \quad-h_{r} \int_{0}^{Q}(Q-x) f(x) d x-h_{r} \int_{0}^{Q}(Q-x) f(x) d x \\
& \quad-s \int_{Q}^{\infty}(x-Q) f(x) d x
\end{aligned}
$$

In Eq. (3), the first term is the collection cost of the used products, the second term is the delivery cost of the used products, the third term is the disassembly and the inspection costs of the used products, the fourth term is the remanufacturing cost of recyclable parts after disassembly of the used products, the fifth term is the disposal cost of un-recycled parts, the sixth term is the procurement cost of new parts, and the seventh term is the production cost of product. The eighth term is the expected product sales, the ninth term is the expected inventory holding cost of the unsold products the final term is the expected shortage penalty cost for unsatisfied product demand in a market. From Eq. (3), it can be seen that the terms regarding the wholesales of products and the compensation for the collection incentive occurring between a retailer and a manufacturer are canceled 
out. Therefore, the whole SC's expected profit is unaffected by the compensation for the collection incentive.

Next, the retailer's expected profit in scenario $2(i=2)$ of the product demand is discussed. Here, the retailer's expected profit $E^{1}\left[\pi_{R}(Q, t, u)\right]$ in scenario $1(i=1)$ of the product demand for $Q, t$ and $u$ in Eq. (3) can be rewritten as follows:

$$
\begin{aligned}
E^{1} & {\left[\pi_{R}(Q, t, u)\right]=-t A(t)-c_{t} A(t) } \\
& +R(t) \int_{u}^{1} g(\ell) A(t) d \ell+(p-w) Q \\
& -\left(p+h_{r}\right) \int_{0}^{Q}(Q-x) f(x) d x \\
& -s \int_{Q}^{\infty}(x-Q) f(x) d x
\end{aligned}
$$

The elicitation process of Eq. (4) is shown in Appendix A.

When mean $\mu$ and variance $\sigma^{2}$ of the demand $x$ are known, the upper limit of the expected excessive inventory quantity and the upper limit of the shortage quantity which demand $x$ is unsatisfied with order quantity $Q$ are derived using the distribution-free approach (DFA: Gallego and Moon, 1993; Moon and Gallego, 1994; Moon and Choi, 1995; Alfares and Elmorra, 2005) as

$$
\begin{aligned}
& E[x-Q]^{+} \leq\left\{\sqrt{\sigma^{2}+(Q-\mu)^{2}}-(Q-\mu)\right\} / 2, \\
& E[Q-x]^{+} \leq\left\{\sqrt{\sigma^{2}+(\mu-Q)^{2}}-(\mu-Q) / 2\right\} .
\end{aligned}
$$

The elicitation processes of Eqs. (5) and (6) are shown in Gallego and Moon (1993) and Alfares and Elmorra (2005).

The lower limit of the retailer's expected profit in $i=2$ can be obtained by applying DFA into the retailer's expected profit in $i=1$. By substituting Eqs. (5) and (6) into the retailer's expected profit $E^{1}\left[\pi_{R}(Q, t, u)\right]$ in scenario $1(i=1)$ of the product demand for $Q, t$ and $u$ in Eq. (4), the lower limit of the retailer's expected profit in $i=2$ for $Q, t$ and $u, E^{2}\left[\pi_{R}(Q, t, u)\right]$, can be derived as

$$
\begin{aligned}
& E^{2}\left[\pi_{R}(Q, t, u)\right]=-t A(t)-c_{t} A(t) \\
& \quad+R(t) \int_{u}^{1} g(\ell) A(t) d \ell+(p-w) Q \\
& \quad-\left(p+h_{r}\right)\left\{\sqrt{\sigma^{2}+(\mu-Q)^{2}}-(\mu-Q)\right\} / 2 \\
& \quad-s\left\{\sqrt{\sigma^{2}+(Q-\mu)^{2}}-(Q-\mu)\right\} / 2
\end{aligned}
$$

The whole SC's expected profit in $i=2, E^{2}\left[\pi_{S}(Q, t\right.$ $u)]$, is obtained as the sum of both members' expected profits in Eqs. (7) and (2), corresponding to

$$
\begin{aligned}
& E^{2}\left[\pi_{S}(Q, t, u)\right]=E^{2}\left[\pi_{R}(Q, t, u)\right]+E\left[\pi_{M}(Q, t, u)\right] \\
& \quad=-t A(t)-c_{t} A(t)-c_{a} A(t)
\end{aligned}
$$

$$
\begin{aligned}
& -A(t) \int_{u}^{1} c_{r}(\ell) g(\ell) d \ell-c_{d} A(t) \int_{0}^{u} g(\ell) d \ell \\
& -c_{n}\left\{Q-A(t) \int_{u}^{1} g(\ell) d \ell\right\}-c_{m} Q \\
& -\left(p+h_{r}\right)\left\{\sqrt{\sigma^{2}+(\mu-Q)^{2}}-(\mu-Q)\right\} / 2 \\
& -s\left\{\sqrt{\sigma^{2}+(Q-\mu)^{2}}-(Q-\mu)\right\} / 2
\end{aligned}
$$

\section{OPTIMAL DECISIONS-MAKING FOR GSC}

\subsection{Decentralized Green Supply Chain}

For the optimal decisions are made under DGSC, the optimal decision approach for the Stackelberg game (Aust and Buscher, 2012; Berr, 2011; Cachon and Netessine, 2004; Cai et al., 2009; Esmaeili and Zeephongsekul, 2010; Hu et al., 2011; Leng and Parlar, 2009; Liu et al., 2012; Mukhopadhyay et al., 2011; Xu et al., 2012; Yan and Sun, 2012; Watanabe et al., 2013) is adopted. The reason why the Stackelberg game is adopted under DGSC of this paper is shown as follows: the optimal decision in the Stackelberg game is made under a situation consisting of one leader of the decision-making and one (multiple) follower(s). First, a leader of the decisionmaking makes the optimal decision so as to the leader's profit. Next, one (multiple) follower(s) make(s) the optimal decision(s) so as to maximize the follower(s)' profit(s) under the optimal decision made by the leader of the decision-making. Suppose that decision variable(s) of supply chain members affect(s) not only the optimal decision so as to maximize the profit of a supply chain member, but also that (those) of the other supply chain member(s), interacting between supply chain members' profit. Under the situation, the optimal decision approach in the Stackelberg game is adopted effectively among supply chain members (Aust and Buscher, 2012; Berr, 2011; Cachon and Netessine, 2004; Cai et al., 2009; Esmaeili and Zeephongsekul, 2010; Hu et al., 2011; Leng and Parlar, 2009; Liu et al., 2012; Mukhopadhyay et al., 2011; Xu et al., 2012; Yan and Sun, 2012; Watanabe et al., 2013). This paper regards a retailer as the leader of the decision-making under DGSC and regards a manufacture as the follower of the decision-making of the retailer under DGSC. The reason is due to the following situation: a retailer not only pays the unit collection incentives $t$ to collect used products from a market so as to cooperate the encouragement the manufacturer's recycling activity of used products, but also faces stochastic demands of products in a market, sells the products in the market and earns the most profit in the entire supply chain.

The retailer determines the optimal order quantity $Q_{D}^{i^{*}}(i=1,2)$ in scenario $i(=1,2)$ of the product demand and the optimal unit collection incentive $t_{D}^{*}$ so as to ma- 
ximize the retailer's expected profit. The manufacturer determines the optimal lower limit of quality level $u_{D}^{*}$ so as to maximize the manufacturer's expected profit under the optimal order quantity $Q_{D}^{i *}$ and the optimal unit collection incentive $t_{D}^{*}$ determined by the retailer. Next, the manufacturer produces the same quality of the optimal order quantity $Q_{D}^{i *}$ and sells the product to the retailer at the unit wholesale price $w$. The procedure for the optimal decision-making $\left(Q_{D}^{i *}, t_{D}^{*}, u_{D}^{*}\right)$ under DGSC is explained as follows. First, the optimal order quantity $Q_{D}^{1^{*}}$ in $i=1$ under DGSC is discussed. The optimal order quantity under DGSC $Q_{D}^{1^{*}}$ in $i=1$ is determined under $t$ and $u$ so as to maximize the expected profit of a retailer who is the leader of the decision-making under DSC. A manufacturer follows the optimal order quantity under DGSC $Q_{D}^{1^{*}}$ in $i=1$ determined by the retailer.

Proposition 1: The retailer's expected profit in $i=1$ in Eq. (1) is the concave function in terms of the order quantity $Q$ under $t$ and $u$.

Proof: The first- and second-order differential equations between the order quantity $Q$ and the expected profit $E^{1}\left[\pi_{R}(Q \mid t, u)\right]$ of the retailer in $i=1$ in Eq. (1) under $t$ and $u$ are derived as follows:

$$
\begin{aligned}
& d E^{1}\left[\pi_{R}(Q \mid t, u)\right] / d Q \\
& \quad=-w+p+s-\left(p+h_{r}+s\right) \int_{0}^{Q} f(x) d x, \\
& d^{2} E^{1}\left[\pi_{R}(Q \mid t, u)\right] / d Q^{2}=-\left(p+h_{r}+s\right) f(Q) .
\end{aligned}
$$

The elicitation processes of Eq. (9) is shown in Appendix B. It is derived that Eq. (10) is negative since it is natural to satisfy the condition $p>0, h_{r}>0, s>0$. The theoretical analysis results in Proposition 1.

Proposition 2: The optimal order quantity $Q_{D}^{1 *}$ in $i=1$ can be obtained as the following unique solution to maximize Eq. (1):

$$
Q_{D}^{l^{*}}=F^{-1}\left(\frac{-w+p+s}{p+h_{r}+s}\right) .
$$

Proof: The solution of $d E^{1}\left[\pi_{R}(Q \mid t, u)\right] / d Q=0$ substituting 0 into Eq. (9) results in Proposition 2.

Next, the optimal order quantity $Q_{D}^{2^{*}}$ in $i=2$ under DGSC is discussed. The optimal order quantity under DGSC $Q_{D}^{2^{*}}$ in $i=2$ is determined under $t$ and $u$ so as to maximize the expected profit of a retailer who is the leader of the decision-making under DSC. A manufacturer follows the optimal order quantity under DGSC $Q_{D}^{2^{*}}$ in $i=2$ determined by the retailer.

Proposition 3: The retailer's expected profit in $i=2$ in Eq. (7) is the concave function in terms of the order quantity $Q$ under $t$ and $u$.
Proof: The first- and second-order differential equations between the order quantity $Q$ and the retailer's expected profit $E^{2}\left[\pi_{R}(Q \mid t, u)\right]$ in $i=2$ in Eq. (7) under $t$ and $u$ are derived as follows:

$$
\begin{aligned}
& d E^{2}\left[\pi_{R}(Q \mid t, u)\right] / d Q \\
&= \frac{1}{2}\left\{\left(p+s-h_{r}-2 w\right)-\left(p+s+h_{r}\right) \frac{(Q-\mu)}{\left[\sigma^{2}+(Q-\mu)^{2}\right]^{\frac{1}{2}}}\right\} \\
& \frac{d^{2} E^{2}\left[\pi_{R}(Q, t, u)\right]}{d Q^{2}}=-\frac{\sigma^{2}\left(p+s+h_{r}\right)}{2\left[\sigma^{2}+(Q-\mu)^{2}\right]^{\frac{3}{2}}} .
\end{aligned}
$$

The elicitation processes of Eqs. (12) and (13) are shown in Appendix C. It is derived that Eq. (13) is negative since it is natural to satisfy the condition $p>0, h_{r}>0$, $s>0$. The theoretical analysis results in Proposition 3 .

Proposition 4: The optimal order quantity $Q_{D}^{2^{*}}$ in $i=2$ can be obtained as the following unique solution to maximize Eqs. (14) and (15):

$$
\begin{aligned}
& Q_{D}^{2^{*}}=\frac{\mu+\sigma y_{D}}{\sqrt{1-y_{D}^{2}}}, \\
& y_{D}=\frac{p+s-h_{r}-2 w}{p+h_{r}+s} .
\end{aligned}
$$

Proof: The solution of $d E^{2}\left[\pi_{R}(Q \mid t, u)\right] / d Q=0$ substituting 0 into equation (12) results in Proposition 4.

Next, under the optimal order quantity in each scenario $i$ of the product demand, $Q_{D}^{i *}(i=1,2)$, in Eqs. (11), (14), and (15), the optimal unit collection incentive $t_{D}^{*}$ and the optimal lower limit of quality level $u_{D}^{*}$ under DGSC are determined independently from standpoints where the retailer is the leader of the decision-making and the manufacturer is the follower of the decisionmaking.

The following first-order differential equation between the lower limit of quality level $u$ and the expected profit $E\left[\pi_{M}(u) \mid Q_{D}^{i *}, t\right](i=1,2)$ of the manufacturer in Eq. (2) under the optimal order quantity $Q_{D}^{i *}(i=1,2)$ and the unit collection incentive $t$ is obtained as

$$
\begin{aligned}
& \frac{d E\left[\pi_{M}(u) \mid Q_{D}^{i^{*}}, t\right]}{d u}(i=1,2) \\
& \quad=A(t) d(u)\left\{c_{r}(u)+R(t)-c_{d}-c_{n}\right\} .
\end{aligned}
$$

The elicitation process of Eq. (16) is shown in Appendix D.

Here, Eq. (16) is zero if and only if to satisfy the following condition:

$$
c_{r}(u)+R(t)-c_{d}-c_{n}=0
$$


Here, from Eq. (6) in Section 3.2 model assumptions, it can be seen that that there is the unique lower limit of quality level $u$ to satisfy Eq. (17) under $t$. We define the lower limit of quality level $u$ to satisfy Eq. (17) as the provisional lower limit of quality level $u_{D}(t)$ determined under $t$. It can be seen that $u_{D}(t)$ maximizes the expected profit $E\left[\pi_{M}(u) \mid Q_{D}^{i^{*}}, t\right](i=1,2)$ under $Q_{D}^{i^{*}}(i$ $=1,2)$ and $t$. By varying $t$ within the range where $0 \leq t$ $\leq t_{U}, t$ and $u_{D}(t)$ are substituted into the Eq. (1) under $Q_{D}^{1^{*}}$ and Eq. (7) under $Q_{D}^{2^{*}}$. The optimal combination $\left(t_{D}^{*}\right.$, $\left.u_{D}^{*}\right)$ is determined as the combination $\left(t, u_{D}(t)\right)$ to maximize the retailer's expected profit $E\left[\pi_{R}\left(t, u_{D}(t)\right) \mid Q_{D}^{i *}\right]$ $(i=1,2)$ Therefore, the optimal unit collection incentive $t_{D}^{*}$ and the optimal lower limit of quality level $u_{D}^{*}$ are determined mutually between members. The expected profits of each member and the whole SC under DGSC can be obtained by using the optimal decisions $\left(Q_{D}^{i *}, t_{D}^{*}\right.$, $\left.u_{D}^{*}\right)(i=1,2)$.

\subsection{Integrated Green Supply Chain}

In IGSC, the optimal decisions regarding order quantity $Q_{C}^{i^{*}}(i=1,2)$ in scenario $i(=1,2)$ of the product demand, the unit collection incentive $t_{C}^{*}$ and the lower limit of quality level $u_{C}^{*}$ are made so as to maximize the whole SC's expected profit. First, the optimal order quantity $Q_{C}^{1^{*}}$ in $i=1$ under IGSC is discussed.

The optimal order quantity under IGSC $Q_{C}^{1^{*}}$ in $i=1$ is determined under $t$ and $u$ so as to maximize the expected profit of the whole SC in Eq. (3). A retailer and a manufacturer follow the optimal order quantity under IGSC $Q_{C}^{1^{*}}$ in $i=1$

Proposition 5: The whole SC's expected profit in $i=1$ in Eq. (3) is the concave function in terms of the order quantity $Q$ under $t$ and $u$.

Proof: The first- and second-order differential equations between the order quantity $Q$ and the whole SC's expected profit $E^{1}\left[\pi_{S}(Q \mid t, u)\right]$ in $i=1$ in Eq. (3) under $t$ and $u$ are derived as follows:

$$
\begin{aligned}
& d E^{1}\left[\pi_{S}(Q \mid t, u)\right] / d Q \\
& \quad=-c_{n}-c_{m}+p+s-\left(p+h_{r}+s\right) \int_{0}^{Q} f(x) d x, \\
& d^{2} E^{1}\left[\pi_{R}(Q \mid t, u)\right] / d Q^{2}=-\left(p+h_{r}+s\right) f(Q) .
\end{aligned}
$$

The elicitation processes of Eq. (18) is shown in Appendix E.

It is derived that Eq. (19) is negative since it is natural to satisfy the condition $p>0, h_{r}>0, s>0$. The theoretical analysis results in Proposition 5.

Proposition 6: The optimal order quantity $Q_{C}^{1^{*}}$ in $i=1$ can be obtained as the following unique solution to maximize Eq. (3):

$$
Q_{C}^{1^{*}}=F^{-1}\left(\frac{-c_{n}-c_{m}+p+s}{p+h_{r}+s}\right) .
$$

Proof: The solution of $d E^{1}\left[\pi_{R}(Q \mid t, u)\right] / d Q=0$ substituting 0 into Eq. (18) results in Proposition 6.

Next, the optimal order quantity $Q_{C}^{2^{*}}$ in $i=2$ under IGSC is discussed. The optimal order quantity under IGSC $Q_{C}^{2^{*}}$ in $i=2$ is determined under $t$ and $u$ so as to maximize the whole SC's expected profit in Eq. (8). A retailer and a manufacturer follows the optimal order quantity under IGSC $Q_{C}^{2^{*}}$ in $i=2$.

Proposition 7: The whole SC's expected profit in $i=2$ in Eq. (8) is the concave function in terms of the order quantity $Q$ under $t$ and $u$.

Proof: The first- and second-order differential equations between the order quantity $Q$ and the whole SC's expected profit $E^{2}\left[\pi_{S}(Q \mid t, u)\right]$ in $i=2$ in Eq. (8) under $t$ and $u$ are derived as follows:

$$
\begin{aligned}
& d E^{2}\left[\pi_{S}(Q \mid t, u)\right] / d Q \\
&= \frac{1}{2}\left\{\left\{p+s-h_{r}-2\left(c_{m}+c_{n}\right)\right\}-\left(p+s+h_{r}\right) \frac{(Q-\mu)}{\left[\sigma^{2}+(Q-\mu)^{2}\right]^{\frac{1}{2}}}\right\} \\
& \frac{d^{2} E^{2}\left[\pi_{R}(Q, t, u)\right]}{d Q^{2}}=-\frac{\sigma^{2}\left(p+s+h_{r}\right)}{2\left[\sigma^{2}+(Q-\mu)^{2}\right]^{\frac{3}{2}}} .
\end{aligned}
$$

The elicitation processes of Eqs. (21) and (22) are shown in Appendix F.

It is derived that Eq. (22) is negative since it is natural to satisfy the condition: $p>0, h_{r}>0, s>0$. The theoretical analysis results in Proposition 7.

Proposition 8: The optimal order quantity $Q_{C}^{2^{*}}$ in $i=2$ can be obtained as the following unique solution to maximize Eqs. (23) and (24):

$$
\begin{aligned}
& Q_{C}^{2^{*}}=\mu+\sigma \frac{y_{C}}{\sqrt{1-y_{C}^{2}}}, \\
& y_{C}=\frac{p+s-h_{r}-2\left(c_{n}+c_{m}\right)}{p+h_{r}+s} .
\end{aligned}
$$

Proof: The solution of $d E^{2}\left[\pi_{S}(Q \mid t, u)\right] / d Q=0$ substituting 0 into Eq. (21) results in Proposition 8.

Next, under the optimal order quantity in $i(=1,2)$, $Q_{C}^{i^{*}}(i=1,2)$, in Eqs. (20), (23), and (24), the optimal unit collection incentive $t_{C}^{*}$ and the optimal lower limit of quality level $u_{C}^{*}$ are determined under IGSC. As the similar way to determine the optimal lower limit of quality level $u_{D}^{*}$ under DGSC, the optimal lower limit of 
quality level $u_{C}^{*}$ is obtained so as to satisfy generally the following condition:

$$
\begin{aligned}
& d E\left[\pi_{s}\left(u \mid Q_{C}^{i^{*}}, t\right)\right] / d u(i=1,2) \\
& \quad=A(t) g(u)\left\{c_{r}(u)-c_{d}-c_{n}\right\}=0 \\
& \quad \Leftrightarrow c_{r}(u)=c_{d}+c_{n}
\end{aligned}
$$

The elicitation processes of Eq. (25) is shown in Appendix G.

The optimal unit collection incentive $t_{C}^{*}$ is determined so as to maximize the expected profit of the whole $\mathrm{SC}$ in $i(=1,2)$ under IGSC, $E\left[\pi_{s}\left(t \mid Q_{c}^{i^{*}}, u_{C}^{*}\right)\right](i=1,2)$, in Eqs. (3) and (8) under $Q_{C}^{i *}(i=1,2)$ in Eqs. (20), (23), and (24), and the optimal lower limit of quality level $u_{C}^{*}$ in Eq. (25). Substituting $Q_{c}^{i *}(i=1,2)$ and $u_{c}^{*}$ into the whole SC's expected profit in $i(=1,2)$ in Eqs. (3) and (8), $t_{C}^{*}$ is determined so as to maximize the whole SC's expected profit $E\left[\pi_{s}\left(t \mid Q_{c}^{i^{*}}, u_{C}^{*}\right)\right](i=1,2)$ by varying $t$ within the range where $0 \leq t \leq t_{U}$. The expected profits of each member and the whole SC under IGSC can be obtained by using the optimal decisions $\left(Q_{C}^{i *}, t_{C}^{*}, u_{C}^{*}\right)(i=1,2)$.

\section{INCORPORAITON OF PROFIT SHAR- ING APPROACH INTO IGSC AS SUP- PLY CHAIN COORPORATION}

As supply chain coordination to guarantee the profit improvement for each member under IGSC, the effects of three profit sharing approaches on the expected profit of each member under IGSC in scenario $i(=1,2)$ of the product demand are discussed. First, the profit sharing 1 adopting the profit ratio between both members is discussed. In the profit sharing 1 , the expected profit of each member under IGSC with supply chain coordination in $i(=1,2)$ is obtained by adding the amount of profit sharing of each member in $i(=1,2), \varphi_{R}^{i}$ and $\varphi_{M}^{i}$, to the expected profit of each member for the optimal decisions in $i(=1,2)$ under DGSC as

$$
\begin{aligned}
& \tilde{E}^{i}\left[\pi_{R}\left(Q_{C}^{i^{*}}, u_{C}^{*}, t_{C}^{*}\right)\right]=E^{i}\left[\pi_{R}\left(Q_{D}^{i^{*}}, u_{D}^{*}, t_{D}^{*}\right)\right]+\varphi_{R}^{i} \\
& \tilde{E}^{i}\left[\pi_{M}\left(Q_{C}^{i^{*}}, u_{C}^{*}, t_{C}^{*}\right)\right]=E^{i}\left[\pi_{M}\left(Q_{D}^{i^{*}}, u_{D}^{*}, t_{D}^{*}\right)\right]+\varphi_{M}^{i} \\
& \varphi_{R}^{i}=\Delta E S^{i} \times E\left[\pi_{R}\left(Q_{C}^{i^{*}}, u_{C}^{*}, t_{C}^{*}\right)\right] / E\left[\pi_{S}\left(Q_{C}^{i^{*}}, u_{C}^{*}, t_{C}^{*}\right)\right] \\
& \varphi_{M}^{i}=\Delta E S^{i} \times E\left[\pi_{M}\left(Q_{C}^{i^{*}}, u_{C}^{*}, t_{C}^{*}\right)\right] / E\left[\pi_{S}\left(Q_{C}^{i^{*}}, u_{C}^{*}, t_{C}^{*}\right)\right] \\
& \Delta E S^{i}=E\left[\pi_{S}\left(Q_{C}^{i^{*}}, u_{C}^{*}, t_{C}^{*}\right)\right]-E\left[\pi_{S}\left(Q_{D}^{i^{*}}, u_{D}^{*}, t_{D}^{*}\right)\right] .
\end{aligned}
$$

Second, the profit sharing 2 adopting the Nash bargaining solutions (Nagarajan and Sosic, 2008; Du et al., 2011) is discussed in order to coordinate the unit wholesale price $w^{i}$ and compensation per used product collected by a retailer at the incentive $t, R^{i}(t)$, in $i(=1,2)$ between both members. Here, $w$ and $R(t)$ are set as $R(t)$ $=(1+\alpha) t$ and $w=w\left(m_{a}\right)=c_{n}+c_{m}+m_{a}$. For simplicity, the degree $\alpha$ of compensation for the retailer's collection incentive $t$ and the margin $m_{a}$ for wholesale per product are coordinated as the Nash bargaining solutions $\alpha^{i N}$ and $m_{a}^{i N}$ in $i(=1,2)$. Substituting $\alpha^{i N}$ and $m_{a}^{i N}$ in $i$ $(=1,2)$ into $w^{i}$ and $R^{i}(t)$, the unit wholesale price $w^{i}$ and the compensation $R^{i}(t)$ in $i(=1,2)$ are calculated. The coordinated $\alpha^{i N}$ and $m_{a}^{i N}$ in $i(=1,2)$ are determined so as to satisfy the following equations:

$$
\begin{aligned}
\operatorname{Max} & T\left(\alpha^{i N}, m_{a}^{i N}\right)(i=1,2) \\
= & \left\{\pi_{R}^{i N}\left(\alpha^{i N}, m_{a}^{i N} \mid Q_{C}^{i *}, t_{C}^{*}, u_{C}^{*}\right)-\pi_{R}^{i}\left(\alpha, m_{a} \mid Q_{D}^{i *}, t_{D}^{*}, u_{D}^{*}\right)\right\} \\
\times & \left.\times \pi_{M}^{i N}\left(\alpha^{i N}, m_{a}^{i N} \mid Q_{C}^{i *}, t_{C}^{*}, u_{C}^{*}\right)-\pi_{M}^{i}\left(\alpha, m_{a} \mid Q_{D}^{i *}, t_{D}^{*}, u_{D}^{*}\right)\right\}
\end{aligned}
$$

subject to

$$
\begin{aligned}
& \pi_{R}^{i N}\left(\alpha^{i N}, m_{a}^{i N} \mid Q_{C}^{i *}, t_{C}^{*}, u_{C}^{*}\right)-\pi_{R}^{i}\left(\alpha, m_{a} \mid Q_{D}^{i *}, t_{D}^{*}, u_{D}^{*}\right)>0 \\
& \pi_{M}^{i N}\left(\alpha^{i N}, m_{a}^{i N} \mid Q_{C}^{i^{*}}, t_{C}^{*}, u_{C}^{*}\right)-\pi_{M}^{i}\left(\alpha, m_{a} \mid Q_{D}^{i *}, t_{D}^{*}, u_{D}^{*}\right)>0
\end{aligned}
$$

where Eqs. (32) and (33) are the constraint conditions to guarantee that the expected profit of each member with supply chain coordination is always higher than that without supply chain coordination.

Third, the profit sharing 3 combining profit sharing 1 with profit sharing 2 is discussed. Here, a retailer is the leader of the decision-making under DGSC and a manufacturer is the follower of the decision-making made by the retailer. Under the situation, this paper considers that it is necessary that the increment of the retailer's expected profit in Eq. (32) is larger than that of the manufacturer's expected profit in Eq. (33) when the optimal decision is shifted from DGSC to IGSC. Therefore, the profit sharing 3 adds the following new constraint condition:

$$
\begin{aligned}
& \pi_{R}^{i N}\left(\alpha^{i N}, m_{a}^{i N} \mid Q_{C}^{i^{*}}, t_{C}^{*}, u_{C}^{*}\right)-\pi_{R}^{i}\left(\alpha, m_{a} \mid Q_{D}^{i^{*}}, t_{D}^{*}, u_{D}^{*}\right) \\
& \quad>\pi_{M}^{i N}\left(\alpha^{i N}, m_{a}^{i N} \mid Q_{C}^{i^{*}}, t_{C}^{*}, u_{C}^{*}\right)-\pi_{M}^{i}\left(\alpha, m_{a} \mid Q_{D}^{i^{*}}, t_{D}^{*}, u_{D}^{*}\right)
\end{aligned}
$$

to the constraint conditions in profit sharing 2 .

\section{NUMERICAL EXPERIMENTS}

In this section, the results of the optimal decisions under DGSC are compared with those under IGSC as to two scenarios of the product demand; scenario $1(i=1)$ : the distribution of product demand is known and scenario $2(i=2)$ : the product demand has unknown distribution with known mean and known variance. The optimal order quantity, the optimal unit collection incentive, the optimal lower limit of quality level and the expect profits of a retailer, a manufacturer and the whole 
SC under DGSC are compared with those under IGSC as to the scenario $i(=1,2)$ of the product demand. Also, the effect of the quality of the recyclable parts in used products on the optimal decisions and the expected profits is shown. Moreover, as supply chain coordination, the effects of three profit sharing approaches: I) Adoption of profit ratio between members, II) Adoption of Nash bargaining solution, III) Adoption of the combination of profit sharing approaches (I) and (II) on each members' profit under IGSC are shown. We used the following system parameter values for numerical examples: $p=150, s=175, h_{r}=15, c_{a}=1, c_{d}=1, c_{t}=1, c_{n}=35$, $c_{m}=2, m_{a}=15$. Regarding the scenario of the product demand $x, x$ follows the normal distribution with the mean $\mu=1000$ and variance $\sigma^{2}=300$ in scenario $1(i=1)$, meanwhile mean and variance of $x$ are knows as $\mu=$ 1000 and $\sigma^{2}=300$ in scenario $2(i=2)$. Further, $A(t), w$ and $c_{r}(\ell)$ are set as $A(t)=100+50 t\left(0 \leq t \leq t_{U}, t_{U}=p\right)$, $=c_{n}+c_{m}+m_{a}, c_{r}(\ell)=40(1-0.9 \ell)$, satisfying the conditions of Eqs. (3), (4), and (6) in model assumptions. Moreover, $R(t)$ is defined as $R(t)=(1+\alpha) t$, where $\alpha$ denotes degree of compensation for the retailer's unit collection incentive $t$ without any supply chain coordination. Here, $\alpha=0.7$ is set in aspect of a manufacturer's profit.

As shown in Figure 1, we assume some shapes of the distribution of quality level $\ell(0 \leq \ell \leq 1)$ of recyclable parts in used products. We model each shape of the distribution of quality level $\ell(0 \leq \ell \leq 1)$ of recyclable parts by using the beta distribution. This is the reason why we use the beta distribution is not only because it's possible to express various shapes, but more important, it's widely used to measure relative parameters like level 1 , or anything that is between $0-1$. Concretely, the beta distribution can express various shapes of distribution of recyclable parts in used products such as the uniform distribution-type shape, the normal distributiontype shape, the exponential distribution-type shape, the left-biased distribution shape, the right-biased distribu-

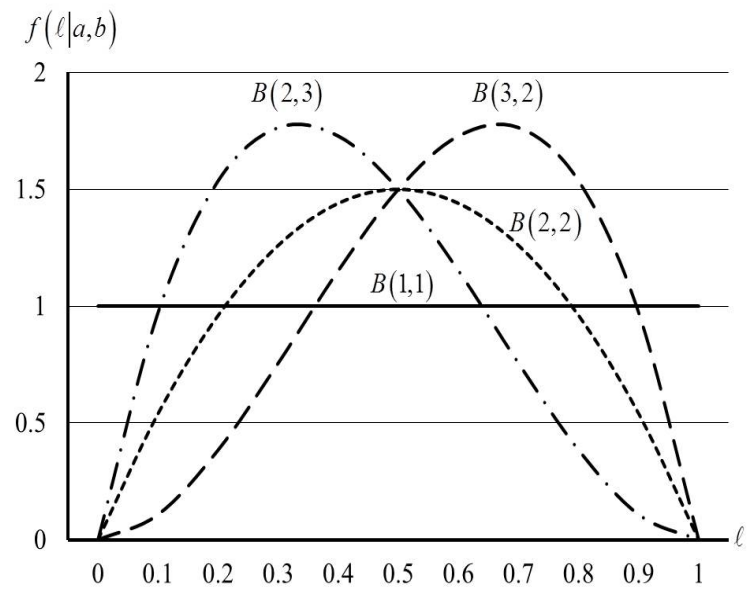

Figure 1. Four cases of distribution of quality level $\ell(0 \leq \ell \leq 1)$ of recyclable parts in used proucts modeled as the beta distribution $B(\ell \mid a, b)$. tion shape, by using the following probability density function with parameters $(a, b)$ :

$$
f(\ell \mid a, b)=\frac{\Gamma(a+b)}{\Gamma(a) \Gamma(b)} \ell^{m-1}(1-\ell)^{n-1},
$$

where $\Gamma(\cdot)$ denotes the gamma function. As shown in Figure 1, we provide four cases of the beta distribution:

Case $1 B(\ell \mid 1,1)$ : the situation where each quality of recyclable parts are uniformly distributed, corresponding to the uniform distribution-type shape for quality level $\ell(0 \leq \ell \leq 1)$,

Case $2 B(\ell \mid 2,2)$ : the situation where there are the more recyclable parts with the middle quality and each quality of recyclable parts are symmetrically distributed, corresponding to the normal distributiontype shape for quality level $\ell(0 \leq \ell \leq 1)$,

Case $3 B(\ell \mid 3,2)$ : the situation where there are the more recyclable parts with the relatively high quality, corresponding to the right-biased distribution shape for quality level $\ell(0 \leq \ell \leq 1)$,

Case $4 B(\ell \mid 2,3)$ : the situation where there are the more recyclable parts with the relatively low quality, corresponding to the left-biased distribution shape for quality level $\ell(0 \leq \ell \leq 1)$.

By changing parameters $(a, b)$ of the probability density function of the beta distribution in Eq. (35), we can see how the results of the optimal operations in the GSC change.

Table 1 shows the comparisons of the optimal order quantity $Q_{j}^{i^{*}}(i=1,2 . j=D, C)$ under DGSC and IGSC as to scenario $i(=1,2)$ of the product demand. From Table 1 , the optimal order quantities, $Q_{D}^{2^{*}}$ and $Q_{C}^{2^{*}}$, in $i=2$ are smaller than those in $i=1$. This is the reason why the available demand information is limited in $i=2$, so the optimal order quantities are determined more carefully in $i=2$ than those are done in $i=1$. Moreover, in scenario $i(=1,2)$, the optimal order quantity $Q_{C}^{i^{*}}$ under IGSC are larger than those under DGSC. This reason is clear from the analysis results regarding the optimal order quantity in Eqs. (11) and (20) and in $i=1$, Eqs. (14), (15), (23) and (24) in $i=2$ under the general condition where $w>c_{n}+c_{m}$. That is, the optimal order quantity $Q_{D}^{i *}$ under DGSC are affected by the unit price $w$, meanwhile the optimal order quantity $Q_{C}^{i^{*}}$ under IGSC are affected by the sum of the procurement cost and the production cost of product, $c_{n}+c_{m}$, satisfying the general condition $w>c_{n}+c_{m}$.

Table 2 shows the comparisons of the optimal lower limit of quality level $u_{j}^{i *}(i=1,2 . j=D, C)$ under DGSC and IGSC and the optimal unit collection incentive $t_{j}^{i^{*}}$ under DGSC and IGSC. From Eqs. (17) and (25), $u_{j}^{i^{*}}$ is unaffected by $Q_{j}^{i^{*}}$ in each scenario of the product demand. From numerical search, it is confirmed that $t_{j}^{i *}$ was unaffected by any scenario of the product demand.

Table 3 shows the comparisons of the expected 
Table 1. Comparisons of optimal order quantity under DGSC and IGSC as to available demand information $(i=1,2)$

\begin{tabular}{|c|c|c|c|c|}
\hline \multirow{3}{*}{$\begin{array}{l}\text { Conditions of distribution of the quality level } \\
\qquad \ell(0 \leq \ell \leq 1) \text { of recyclable parts }\end{array}$} & \multicolumn{4}{|c|}{ Optimal order quantity } \\
\hline & DGSC & IGSC & DGSC & IGSC \\
\hline & $Q_{D}^{1^{*}}$ & $Q_{D}^{2^{*}}$ & $Q_{C}^{1^{*}}$ & $Q_{C}^{2^{*}}$ \\
\hline Case $1 B(\ell \mid 1,1)$ & 1256 & 1228 & 1307 & 1289 \\
\hline Case $2 B(\ell \mid 2,2)$ & 1256 & 1228 & 1307 & 1289 \\
\hline Case $3 B(\ell \mid 3,2)$ & 1256 & 1228 & 1307 & 1289 \\
\hline Case $4 B(\ell \mid 2,3)$ & 1256 & 1228 & 1307 & 1289 \\
\hline
\end{tabular}

DGSC: decentralized green supply chain, IGSC: integrated green supply chain.

Table 2. Comparisons of the optimal unit collection incentive and the optimal lower limit of quality level of recyclable parts under DGSC and IGSC

\begin{tabular}{|c|c|c|c|c|}
\hline \multirow{3}{*}{$\begin{array}{l}\text { Conditions of distribution of the quality level } \\
\qquad \ell(0 \leq \ell \leq 1) \text { of recyclable parts }\end{array}$} & \multicolumn{2}{|c|}{$\begin{array}{c}\text { Optimal unit } \\
\text { collection incentive }\end{array}$} & \multicolumn{2}{|c|}{$\begin{array}{c}\text { Optimal unit } \\
\text { collection incentive }\end{array}$} \\
\hline & DGSC & IGSC & DGSC & IGSC \\
\hline & $t_{D}^{*}$ & $t_{C}^{*}$ & $u_{D}^{*}$ & $u_{C}^{*}$ \\
\hline Case $1 B(\ell \mid 1,1)$ & 2.94 & 4.61 & 0.25 & 0.11 \\
\hline Case $2 B(\ell \mid 2,2)$ & 3.94 & 4.52 & 0.30 & 0.11 \\
\hline Case $3 B(\ell \mid 3,2)$ & 6.13 & 6.30 & 0.40 & 0.11 \\
\hline Case $4 B(\ell \mid 2,3)$ & 2.27 & 2.74 & 0.22 & 0.11 \\
\hline
\end{tabular}

DGSC: decentralized green supply chain, IGSC: integrated green supply chain.

Table 3. Comparisons of expected profits of retailer and the whole SC under DGSC for scenarios 1 and 2 of product demand

\begin{tabular}{ccccc}
\hline \multirow{2}{*}{$\begin{array}{c}\text { Conditions of distribution of the quality } \\
\text { level of recyclable parts }\end{array}$} & \multicolumn{2}{c}{ Retailer's expected profit } & \multicolumn{2}{c}{ The whole SC's expected profit } \\
\cline { 2 - 5 } & $\begin{array}{c}\text { Scenario 1 of } \\
\text { product demand }\end{array}$ & $\begin{array}{c}\text { Scenario 2 of } \\
\text { product demand }\end{array}$ & $\begin{array}{c}\text { Scenario 1 of } \\
\text { product demand }\end{array}$ & $\begin{array}{c}\text { Scenario } 2 \text { of } \\
\text { product demand }\end{array}$ \\
\hline Case $1 B(\ell \mid 1,1)$ & 69582 & 57380 & 91003 & 78472 \\
Case $2 B(\ell \mid 2,2)$ & 69729 & 57526 & 90946 & 78415 \\
Case $3 B(\ell \mid 3,2)$ & 70205 & 58003 & 92265 & 79734 \\
Case $4 B(\ell \mid 2,3)$ & 69583 & 57380 & 89943 & 77412
\end{tabular}

SC: supply chain, DGSC: decentralized green supply chain.

profits of retailer and the whole SC under DGSC for scenario 1 and scenario 2 of product demand. It can be seen that all the expected profits with DFA under scenario 2 are guaranteed to be lower than those under scenario 1 .

Next, the optimal unit collection incentive $t_{D}^{*}$ under DGSC are compared with the optimal unit collection incentive $t_{C}^{*}$ under IGSC in cases $1-4$ for the distribution of the quality level $\ell$ of recyclable parts. From Table 2, it can be seen that $t_{D}^{*}$ and $t_{C}^{*}$ are affected by for cases $1-4$ of $\ell$. In case 3 , the more parts tend to be remanufactured, since $\ell$ is relatively high quality. This is the reason why $t_{D}^{*}$ and $t_{C}^{*}$ are determined as higher values indicating that more used products tend to be collected under the higher unit collection incentives. Mean- while, in case 4, the less parts tend to be remanufactured, since $\ell$ is relatively low quality. This is the reason why $t_{D}^{*}$ and $t_{C}^{*}$ are determined as lower values indicating that less used products tend to be collected under the lower unit collection incentives .

Moreover, the optimal unit collection incentive $t_{D}^{*}$ under DGSC are compared with the optimal unit collection incentive $t_{C}^{*}$ under IGSC. From Eq. (1) in $i=1$ and Eq. (7) in $i=2$ regarding the retailer's expected profit, $t_{D}^{*}$ is affected by the compensation income. Meanwhile, from Eq. (3) in $i=1$ and Eq. (8) in $i=2$, regarding the whole SC's expected profit, $t_{C}^{*}$ is unaffected by the compensation income, but $t_{C}^{*}$ is affected by the disassembly and inspection cost of the used products, the remanufacturing cost of the recyclable parts, the disposal cost of 
un-reused parts and the procurement cost of new parts. This is the reason why $t_{C}^{*}$ is determined as higher value than $t_{D}^{*}$ in Table 2 . It implies that the collection quantity of used products under IGSC is more than that under DGSC. In Table 2, we also compare $u_{D}^{*}$ with $u_{C}^{*}$ From the Eq. (17), $u_{D}^{*}$ is affected by $t_{D}^{*}$ determined by the retailer. Meanwhile, from the Eq. (25), $u_{C}^{*}$ is unaffected by $t_{D}^{*}$, since the term of compensation is canceled out between both members under IGSC. Also, from Eqs. (17) and $(25), u_{C}^{*}$ can be determined as lower values than $u_{D}^{*}$. This fact implies that the recycling of the used products can be encouraged under IGSC. This feature can be confirmed from the results of numerical analysis, $u_{D}^{*}$ and $u_{C}^{*}$, in Table 2. Also, $u_{D}^{*}$ is compared with $u_{C}^{*}$ under cases 1-4 for the distribution of the quality level $\ell$ of recyclable parts. It can be seen that $u_{C}^{*}$ is unaffected by any condition of distribution of $\ell$ of them. This is the reason why the compensation relevant to the probability distribution of $\ell$ of them is canceled out between members under IGSC. Meanwhile, $u_{D}^{*}$ is affected by each condition of distribution of $\ell$ of them.

Furthermore, the expected profits of the retailer, the manufacturer under DGSC are compared with those under IGSC as to scenario $i(=1,2)$ of the product demand. Table 4 shows the results for $i=1$ in cases $1-4$ of the distribution of the quality level $\ell$ of recyclable parts. From Table 4, the expected profit of the manufacturer in each case under IGSC is higher than that under DGSC. Only in case 4 under $i=1$ in Table 4 , the expected profit of the retailer under IGSC is lower than that under DGSC. In other cases under $i=1$ in Table 4 , the expected prof- its of both members under IGSC are higher than those under DGSC. However, the manufacturer has the more increment of the profit obtained under IGSC than the retailer has under IGSC. This result is same in scenario $i=2$. This implies that the increment of the expected profit for each member under IGSC does not reflect the size of the expected profit of each member. It is difficult for the retailer to shift the optimal decisions under IGSC which can enhance the expected profit of the whole SC.

Under the situation, any reasonable profit sharing is necessary between members under IGSC so as to shift to the optimal decisions under IGSC from those under DGSC, guaranteeing more profits to members under IGSC than those under DGSC. The effects of profit sharing approach under IGSC on the expected profits of the retaler and the manufacturer are investigated. Table 5 shows the effects of supply chain coordination adopting each profit sharing approach described in Section 6. for Case 1 of the distribution of the quality level $\ell(0 \leq \ell \leq 1)$ of recyclable parts in scenario $1(i=1)$ where the expected profit of the retailer is lower under IGSC. From the results of Table 5 , it can be seen that the expected profits of members under IGSC with all profit sharing approaches are higher than those under DGSC in any condition of distribution of the quality level $\ell$ of them. Moreover, the superiority is compared between three profit sharing approaches. In the profit sharing approach 1 , the increment of the expected profit obtained under IGSC is shared between members without any adjustment of parameters regarding supply chain coordination contract between both members. It may be difficult to accept the

Table 4. Comparisons of expected profits of both members under DGSC and IGSC in available demand information $i=1$

\begin{tabular}{clccc}
\hline $\begin{array}{c}\text { Conditions of distribution of the quality } \\
\text { level of recyclable parts }\end{array}$ & \multicolumn{2}{c}{ Retailer's expected profit } & \multicolumn{3}{c}{ Manufacturer's expected profit } \\
\cline { 2 - 5 } Case $1 B(\ell \mid 1,1)$ & DGSC & IGSC & DGSC & IGSC \\
Case $2 B(\ell \mid 2,2)$ & 69582 & $69659(+77)$ & 20841 & $21345(+504)$ \\
Case $3 B(\ell \mid 3,2)$ & 69729 & $69830(+101)$ & 20648 & $21116(+468)$ \\
Case $4 B(\ell \mid 2,3)$ & 70205 & $70603(+398)$ & 21226 & $21661(+435)$ \\
\end{tabular}

DGSC: decentralized green supply chain, IGSC: integrated green supply chain.

Table 5. Effects of supply chain coordination in available demand information $i=1$ in case 1 of distribution of $\ell(0 \leq \ell \leq 1)$ of recyclable parts

\begin{tabular}{|c|c|c|c|c|}
\hline \multirow{2}{*}{ Expected profits of GSC } & \multirow{2}{*}{$\begin{array}{c}\text { No profit sharing } \\
\text { DGSC }\end{array}$} & \multicolumn{3}{|c|}{ Profit sharing approach incorporated into IGSC } \\
\hline & & I & II & III \\
\hline Retailer & 69582 & $70029(+447)$ & $69872(+290)$ & $69873(+291)$ \\
\hline Manufacturer & 20841 & $20975(+134)$ & $21131(+290)$ & $21130(+289)$ \\
\hline Whole supply chain & 90424 & $91003(+579)$ & $91003(+579)$ & $91003(+579)$ \\
\hline Coordinated degree of compensation $\alpha^{1 N}$ & 0.7 & 0.7 & 1.63 & 1.34 \\
\hline Coordinated margin $m_{a}^{1 N}$ & 15 & 15 & 15.8 & 15.5 \\
\hline
\end{tabular}

GSC: green supply chain, DGSC: decentralized GSC, IGSC: integrated GSC. 
profit sharing approach 1 between members as supply chain coordination. In the profit sharing approaches 2 and 3 , the increment of the expected profit obtained under IGSC is shared between members, using reasonable parameters regarding the unit whole sales price and the compensation per used product collected by a retailer at the incentive in supply chain coordination contract adjusted by Nash bargaining solutions. Moreover, in the profit sharing approach 3 , it is possible to reflect the size of the expected profit of each member on the amount of profit sharing for each member. For the retailer who is the leader of the decision-making under DGSC, the profit sharing approach 3 is the most reasonable one to encourage all members in GSC to shift to the optimal decisions under IGSC from those under DGSC.

\section{CONCLUSIONS}

This study proposed an optimal production policy for a GSC with material flows from the collection of used products to the reuse of recycled parts in production of products. In the GSC, a retailer paid an incentive for collection of used products from customers and hands them over to a manufacturer. In this case, the retailer placed an order for an order quantity of the products to the manufacturer, considering the product demand uncertainty. The manufacturer disassembled the used products, and then classified the recyclable parts into quality levels by the result of the inspection of the used products. The manufacturer remanufactured products using recyclable parts with acceptable quality levels and paid for compensation a part of the retailer's incentive for collection of used products based on the quantity of the recycled parts to the retailer.

Here, the uncertainty in demand of a single product which a retailer faced in selling the product in a market was assumed as the following scenarios: 1) the distribution of product demand was known, 2) the product demand has unknown distribution with known mean and known variance. For each situation, this paper developed two types of mathematical models and conducted the theoretical analysis in order to find the effect of order quantity, collection incentive of used products and lower limit of quality level for recycling of used products on the expected profits of each member and the whole SC under both DGSC and IGSC. Concretely, two types of optimal decisions were proposed for product quantity, collection incentive of used products and lower limit of quality level for recycling in GSC. One was under DGSC whose objective was to maximize the expected profit of each member. The other was under IGSC whose objective was to maximize the whole SC's expected profit.

The analysis numerically investigated how the following factors: i) available distribution information of product demand, ii) the quality of the recyclable parts after disassembly of used products affected the optimal operation and the expected profits a retailer, a manufacturer and the whole SC under DGSC and IGSC. Additionally, the results of optimal operation under DGSC were compared with those under IGSC under above factors (i) and (ii). Moreover, as supply chain coordination, the effects of three profit sharing approaches on each member's profit were investigated under IGSC: I) adoption of profit ratios between members, II) adoption of Nash bargaining solution, III) adoption of the combination of (I) and (II).

This paper contributed the following managerial insights from outcomes obtained from both the theoretical research and the numerical analysis to both academic researchers and real-world policymakers regarding operations in a GSC:

- The optimal order quantity in the scenario 2 where the product demand had unknown distribution with known mean and known variance was determined as a lower value than the scenario 1 where the distribution of product demand was known. This was due to the situation where the optimal decision in the scenario 2 was made under the worst situation where a retailer obtained the lowest expected profit.

- It was possible to guarantee to bring more profits to all members (a retailer and a manufacturer) in a GSC by taking the more aggressive eco-activity where not only a retailer paid incentive to customers in order to collect the more used products from customers, but also a manufacturer compensated some parts of incentive the retailer paid. Therefore, incorporation of the optimal collection incentive into a GSC could encourage both activities of the collection and the recycling of used products, increasing the expected profits of all members and the whole SC in the GSC.

- It was profitable to determine optimally the lower level of quality of recyclable parts after disassembly of the used products when the quality of recyclable parts was distributed several quality level.

- The optimal lower level of quality of recyclable parts under IGSC could be determined as a lower value than that under DGSC. Also, the optimal collection incentive under IGSC could be determined as a higher value than that under DGSC. Therefore, the optimal decisions under IGSC could encourage the more aggressive eco-activity regarding the collection and the remanufacturing of used products among all members and the whole SC in a GSC.

- From the aspect of profit, incorporation of profit sharing approach into IGSC could promote not only the more aggressive eco-activity among all members in the GSC, but also shift the decision-making under IGSC, guaranteeing the more expected profits of all members and the whole SC in a GSC.

Therefore, it is highly expected that research outcomes in this paper would provide not only the optimal solution and its practices to construct a GSC to encour- 
age both aggressive eco-activities of the collection and the remanufacturing of used products to firms, but also informative motivations for researchers and policymakers regarding operations in a GSC.

In the optimal operation for a GSC proposed in this paper, the optimal collection incentive of used products can be determined as a lower value indicating the less aggressive collection activity of used products. In the situation, there are used products with low quality. So, a manufacturer tends to take an inactive remanufacturing activity. In this case, a retailer tends to obtain the less compensation for the collection inventive of used products from the manufacturer.

As the extendable consideration including the above issue, it will be necessary to discuss the following issues to analyze the optimal operation for a GSC:

- Framework of a GSC to encourage the aggressive ecoactivities regarding the collection and remanufacturing of used products even if there are used products with low quality

- A situation of uncertainty in the collection quantity of the used products

- Limitation of information regarding quality distribution of used products/ recyclable parts

- Alternative supply chain coordination between a retailer and a manufacturer to evaluate the profit balance and cost effectiveness of each member in GSC.

\section{ACKNOWLEDGMENTS}

This research has been supported by the Grant-inAid for Scientific Research C (No. 25350451) from the Japan Society for the Promotion of Science.

\section{REFERENCES}

Alfares, H. K. and Elmorra, H. H. (2005), The distribution-free newsboy problem: extensions to the shortage penalty case, International Journal of Production Economics, 93-94, 465-477.

Aras, N., Boyaci, T., and Verter, V. (2004), The effect of categorizing returned products in remanufacturing, IIE Transactions, 36(4), 319-331.

Aust, G. and Buscher, U. (2012), Vertical cooperative advertising and pricing decisions in a manufacturer-retailer supply chain: a game-theoretic approach, European Journal of Operational Research, 223(2), 473-482.

Bakal, I. S. and Akcali, E. (2006), Effects of random yield in remanufacturing with price-sensitive supply and demand, Production and Operations Management, 15(3), 407-420.

Behret, H. and Korugan, A. (2009), Performance analysis of a hybrid system under quality impact of returns, Computers and Industrial Engineering, 56(2),
507-520.

Berr, F. (2011), Stackelberg equilibria in managerial delegation games, European Journal of Operational Research, 212(2), 251-262.

Cachon, G. P. and Netessine, S. (2004), Game theory in supply chain analysis. In: Simchi-Levi, D., Wu, S. D., and Shen, Z. J. (eds.), Handbook of Quantitative Supply Chain Analysis: Modeling in the $e$ Business Era, Kluwer, Boston, MA, 13-65.

Cai, G. G., Zhang, Z. G., and Zhang, M. (2009), Game theoretical perspectives on dual-channel supply chain competition with price discounts and pricing schemes, International Journal of Production Economics, 117(1), 80-96.

Daniel, V., Guide Jr, R., and Jayaraman, V. (2000), Product acquisition management: current industry practice and a proposed framework, International Journal of Production Research, 38(16), 37793800 .

Du, J., Liang, L., Chen, Y., Cook, W. D., and Zhu, J. (2011), A bargaining game model for measuring performance of two-stage network structures, $E u$ ropean Journal of Operational Research, 210(2), 390-397.

Esmaeili, M. and Zeephongsekul, P. (2010), Sellerbuyer models of supply chain management with an asymmetric information structure, International Journal of Production Economics, 123(1), 146-154.

Ferguson, M., Guide, V. D., Koca, E., and Souza, G. C. (2009), The value of quality grading in remanufacturing, Production and Operations Management, 18 (3), 300-314.

Fleischmann, M., Bloemhof-Ruwaard, J. M., Dekker, R., Van der Laan, E., Van Nunen, J. A., and Van Wassenhove, L. N. (1997), Quantitative models for reverse logistics: a review, European Journal of $\mathrm{Op}$ erational Research, 103(1), 1-17.

Gallego, G. and Moon, I. (1993), The distribution free newsboy problem: review and extensions, Journal of the Operational Research Society, 44(8), 825834.

Guide, V. D. R. and Wassenhove, L. N. (2001), Managing product returns for remanufacturing, Production and Operations Management, 10(2), 142-155.

Guide, V. D. R., Teunter, R. H., and Van Wassenhove, L. N. (2003), Matching demand and supply to maximize profits from remanufacturing, Manufacturing and Service Operations Management, 5(4), 303-316.

Hu, Y., Guan, Y., and Liu, T. (2011), Lead-time hedging and coordination between manufacturing and sales departments using Nash and Stackelberg games, European Journal of Operational Research, 210(2), 231-240.

Inderfurth, K. (2005), Impact of uncertainties on recovery behavior in a remanufacturing environment: a numerical analysis, International Journal of Physical Distribution and Logistics Management, 35(5), 318-336. 
Kaya, O. (2010), Incentive and production decisions for remanufacturing operations, European Journal of Operational Research, 201(2), 442-453.

Konstantaras, I., Skouri, K., and Jaber, M. Y. (2010), Lot sizing for a recoverable product with inspection and sorting, Computers and Industrial Engineering, 58(3), 452-462.

Lee, C., Realff, M., and Ammons, J. (2011), Integration of channel decisions in a decentralized reverse production system with retailer collection under deterministic non-stationary demands, Advanced Engineering Informatics, 25(1), 88-102.

Leng, M. and Parlar, M. (2009), Lead-time reduction in a two-level supply chain: Non-cooperative equilibria vs. coordination with a profit-sharing contract, International Journal of Production Economics, 118(2), 521-544.

Liu, Z. L., Anderson, T. D., and Cruz, J. M. (2012), Consumer environmental awareness and competition in two-stage supply chains, European Journal of Operational Research, 218(3), 602-613.

Moon, I. and Choi, S. (1995), The distribution free newsboy problem with balking, Journal of the Operational Research Society, 46(4), 537-542.

Moon, I. and Gallego, G. (1994), Distribution free procedures for some inventory models, Journal of the Operational Research Society, 45(6), 651-658.

Mukhopadhyay, S. K. and Ma, H. (2009), Joint procurement and production decisions in remanufacturing under quality and demand uncertainty, International Journal of Production Economics, 120(1), 5-17.

Mukhopadhyay, S. K., Yue, X., and Zhu, X. (2011), A Stackelberg model of pricing of complementary goods under information asymmetry, International Journal of Production Economics, 134(2), 424-433.

Nagarajan, M. and Sosic, G. (2008), Game-theoretic analysis of cooperation among supply chain agents: review and extensions, European Journal of $\mathrm{Op}$ erational Research, 187(3), 719-745.

Nenes, G., Panagiotidou, S., and Dekker, R. (2010), Inventory control policies for inspection and remanufacturing of returns: a case study, International Journal of Production Economics, 125(2), 300-312.

Pokharel, S. and Liang, Y. (2012), A model to evaluate acquisition price and quantity of used products for remanufacturing, International Journal of Production Economics, 138(1), 170-176.

Shi, J., Zhang, G., and Sha, J. (2011), Optimal production planning for a multi-product closed loop system with uncertain demand and return, Computers and Operations Research, 38(3), 641-650.

Shi, J., Zhang, G., Sha, J., and Amin, S. H. (2010), Coordinating production and recycling decisions with stochastic demand and return, Journal of Systems Science and Systems Engineering, 19(4), 385-407.

Tagaras, G. and Zikopoulos, C. (2008), Optimal location and value of timely sorting of used items in a remanufacturing supply chain with multiple collection sites, International Journal of Production Economics, 115(2), 424-432.

Teunter, R. H. and Flapper, S. D. P. (2011), Optimal core acquisition and remanufacturing policies under uncertain core quality fractions, European Journal of Operational Research, 210(2), 241-248.

Thierry, M. C., Salomon, M., van Nunen, J. A. E. E., and van Wassenhove, L. N. (1995), Strategic issues in product recovery management, California Management Review, 37(2), 114-135.

Tsay, A. A., Nahmias, S., and Agrawal, N. (1999), Modelling supply chain contracts: a review. In: Tayur, S., Ganeshan, R., and Magazine, M. (eds.), Quantitative Models for Supply Chain Management, Kluwer Academic Publishers, Boston, MA, 299-336.

Van Wassenhove, L. N. and Zikopoulos, C. (2010), On the effect of quality overestimation in remanufacturing, International Journal of Production Research, 48(18), 5263-5280.

Watanabe, T., Kusuawa, E., and Arizono, I. (2013), Optimal operation for green supply chain in consideration of collection incentive and quality for recycling of used products, Industrial Engineering and Management Systems, 12(4), 317-329.

Wei, C., Li, Y., and Cai, X. (2011), Robust optimal policies of production and inventory with uncertain returns and demand, International Journal of Production Economics, 134(2), 357-367.

Wei, J., Zhao, J., and Li, Y. (2012), Pricing decisions for a closed-loop supply chain in a fuzzy environment, Asia-Pacific Journal of Operational Research, 29 (1), 1240003.

Wu, C. H. (2012), Product-design and pricing strategies with remanufacturing, European Journal of Operational Research, 222(2), 204-215.

Xu, J., Jiang, W., Feng, G., and Tian, J. (2012), Comparing improvement strategies for inventory inaccuracy in a two-echelon supply chain, European Journal of Operational Research, 221(1), 213-221.

Yan, N. N. and Sun, B. W. (2012), Optimal Stackelberg strategies for closed-loop supply chain with thirdparty reverse logistics, Asia-Pacific Journal of Operational Research, 29(5), 1250026.

Yano, C. A. and Gilbert, S. M. (2004), Coordinated pricing and production/procurement decisions: a review. In: Chakravarty, A. K. and Eliashberg, J. (eds.), Managing Business Interfaces, Springer, New York, NY, 65-103.

Zikopoulos, C. and Tagaras, G. (2007), Impact of uncertainty in the quality of returns on the profitability of a single-period refurbishing operation, European Journal of Operational Research, 182(1), 205-225.

Zikopoulos, C. and Tagaras, G. (2008), On the attractiveness of sorting before disassembly in remanufacturing, IIE Transactions, 40(3), 313-323. 


\section{APPENDIX A}

$$
\begin{aligned}
E^{2} & {\left[\pi_{R}(Q, t, u)\right]=-t A(t)-c_{t} A(t) } \\
& -w Q+R(t) \int_{u}^{1} g(\ell) A(t) d \ell \\
& +p \int_{0}^{Q}\{Q-(Q-x)\} f(x) d x+p Q \int_{Q}^{\infty} f(x) d x \\
& -h_{r} \int_{0}^{Q}(Q-x) f(x) d x \\
& -s \int_{Q}^{\infty}(x-Q) f(x) d x \\
& =-t A(t)-c_{t} A(t)+R(t) \int_{u}^{1} g(\ell) A(t) d \ell \\
& -w Q+p Q \int_{0}^{Q} f(x) d x+p Q \int_{Q}^{\infty} f(x) d x \\
& -p \int_{0}^{Q}(Q-x) f(x) d x \\
& -h_{r} \int_{0}^{Q}(Q-x) f(x) d x \\
& -s \int_{Q}^{\infty}(x-Q) f(x) d x \\
& =-t A(t)-c_{t} A(t)+R(t) \int_{u}^{1} g(\ell) A(t) d \ell-w Q+p Q \\
& -\left(p+h_{r}\right) \int_{0}^{Q}(Q-x) f(x) d x \\
& -s \int_{Q}^{\infty}(x-Q) f(x) d x
\end{aligned}
$$

Therefore, the elicitation process of Eq. (4) can be shown.

\section{APPENDIX B}

$$
\begin{aligned}
& \frac{d E^{1}\left[\pi_{R}(Q, t, u)\right]}{d Q}=-w \\
& +p \frac{d}{d Q} Q \int_{Q}^{\infty} f(x) d x+p \frac{d}{d Q} \int_{0}^{Q} x f(x) d x \\
& -h_{r} \frac{d}{d Q} \int_{0}^{Q}(Q-x) f(x) d x-s \frac{d}{d Q} \int_{Q}^{\infty}(x-Q) f(x) d x \\
& =-w \\
& +p \frac{d}{d Q} Q \int_{Q}^{\infty} f(x) d x+p \frac{d}{d Q} \int_{0}^{Q}\{Q-(Q-x)\} f(x) d x \\
& -h_{r} \frac{d}{d Q} \int_{0}^{Q} Q f(x) d x+h_{r} \frac{d}{d Q} \int_{0}^{Q} x f(x) d x \\
& -s \frac{d}{d Q} \int_{Q}^{\infty} x f(x) d x+s \frac{d}{d Q} \int_{Q}^{\infty} Q f(x) d x \\
& =-w \\
& +p \frac{d}{d Q} \int_{Q}^{\infty} Q f(x) d x+p \frac{d}{d Q} \int_{0}^{Q} Q f(x) d x \\
& -p \frac{d}{d Q} \int_{0}^{Q}(Q-x) f(x) d x \\
& -h_{r} \frac{d}{d Q} \int_{0}^{Q} Q f(x) d x+h_{r} \frac{d}{d Q} \int_{0}^{Q} x f(x) d x
\end{aligned}
$$

$$
\begin{aligned}
& -s \frac{d}{d Q} \int_{Q}^{\infty} x f(x) d x+s \frac{d}{d Q} \int_{Q}^{\infty} Q f(x) d x \\
& =-w+p \frac{d}{d Q} \int_{0}^{\infty} Q f(x) d x \\
& -p \frac{d}{d Q} \int_{0}^{Q} Q f(x) d x+p \frac{d}{d Q} \int_{0}^{Q} x f(x) d x \\
& -h_{r} \frac{d}{d Q} \int_{0}^{Q} Q f(x) d x+h_{r} \frac{d}{d Q} \int_{0}^{Q} x f(x) d x \\
& -s \frac{d}{d Q} \int_{Q}^{\infty} x f(x) d x+s \frac{d}{d Q} \int_{Q}^{\infty} Q f(x) d x \\
& =-w+p \\
& -p \int_{0}^{Q} f(x) d x-p Q f(Q)+p Q f(Q) \\
& -h_{r} \int_{0}^{Q} f(x) d x-h_{r} Q f(Q)+h_{r} Q f(Q) \\
& +s Q f(Q)+s \int_{Q}^{\infty} f(x) d x-s Q f(Q) \\
& =-w+p \\
& -p \int_{0}^{Q} f(x) d x-h_{r} \int_{0}^{Q} f(x) d x+s\left\{1-\int_{0}^{Q} f(x) d x\right\} \\
& =-w+p+s \\
& -p \int_{0}^{Q} f(x) d x-h_{r} \int_{0}^{Q} f(x) d x-s \int_{0}^{Q} f(x) d x \\
& =-w+p+s-\left(p+h_{r}+s\right) \int_{0}^{Q} f(x) d x
\end{aligned}
$$

Therefore, the elicitation process of Eq. (9) can be shown.

\section{APPENDIX C}

$$
\begin{gathered}
E^{2}\left[\pi_{R}(Q, t, u)\right]=-t A(t)-c_{t} A(t) \\
+R(t) \int_{u}^{1} g(\ell) A(t) d \ell+(p-w) Q \\
-\left(p+h_{r}\right) \frac{\left[\sigma^{2}+(\mu-Q)^{2}\right]^{\frac{1}{2}}-(\mu-Q)}{2} \\
-{ }_{-S} \frac{\left[\sigma^{2}+(Q-\mu)^{2}\right]^{\frac{1}{2}}-(Q-\mu)}{2}
\end{gathered}
$$

Eq. (7) can be rewritten as

$$
\begin{aligned}
& E^{2}\left[\pi_{R}(Q, t, u)\right]=-t A(t)-c_{t} A(t)+R(t) \int_{u}^{1} g(\ell) A(t) d \ell \\
& +\frac{1}{2}\left\{2(p-w) Q-\left(p+h_{r}\right)\left[\sigma^{2}+(\mu-Q)^{2}\right]^{\frac{1}{2}}\right. \\
& \left.\quad+\left(p+h_{r}\right)(\mu-Q)-s\left[\sigma^{2}+(Q-\mu)^{2}\right]^{\frac{1}{2}}+s(Q-\mu)\right\} \\
& \quad=-t A(t)-c_{t} A(t)+R(t) \int_{u}^{1} g(\ell) A(t) d \ell
\end{aligned}
$$




$$
\begin{aligned}
& +\frac{1}{2}\left\{(2 p-2 w) Q+\left(p+h_{r}-s\right)(\mu-Q)\right. \\
& \left.-\left(p+h_{r}+s\right)\left[\sigma^{2}+(\mu-Q)^{2}\right]^{\frac{1}{2}}\right\} \\
& =-t A(t)-c_{t} A(t)+R(t) \int_{u}^{1} g(\ell) A(t) d \ell \\
& +\frac{1}{2}\left\{\left(p+s-h_{r}-2 w\right) Q+\left(p+h_{r}-s\right) \mu\right. \\
& \left.-\left(p+s+h_{r}\right)\left[\sigma^{2}+(Q-\mu)^{2}\right]^{\frac{1}{2}}\right\} . \\
& \frac{d E^{2}\left[\pi_{R}(Q, t, u)\right]}{d Q} \\
& =\frac{1}{2}\left\{\left\{\left(p+s-h_{r}-2 w\right)-\frac{d}{d Q}\left(p+s+h_{r}\right)\left[\sigma^{2}+(Q-\mu)^{2}\right]^{\frac{1}{2}}\right\}\right. \\
& =\frac{1}{2}\left\{\left(p+s-h_{r}-2 w\right)-\left(p+s+h_{r}\right) \frac{(Q-\mu)}{\left[\sigma^{2}+(Q-\mu)^{2}\right]^{\frac{1}{2}}}\right\}
\end{aligned}
$$

Therefore, the elicitation process of Eq. (12) can be shown.

$$
\begin{aligned}
& \frac{d^{2} E^{2}\left[\pi_{R L}(Q, t, u)\right]}{d Q^{2}} \\
& =\frac{1}{2} \cdot \frac{d}{d Q}\left\{\left(p+s-h_{r}-2 w\right)\right. \\
& \left.-\left(p+s+h_{r}\right) \frac{(Q-\mu)}{\left[\sigma^{2}+(Q-\mu)^{2}\right]^{\frac{1}{2}}}\right\} \\
& =-\frac{d}{d Q} \frac{\left(p+s+h_{r}\right)(Q-\mu)}{2\left[\sigma^{2}+(Q-\mu)^{2}\right]^{\frac{1}{2}}} \\
& =-\frac{\sigma^{2}\left(p+s+h_{r}\right)}{2\left[\sigma^{2}+(Q-\mu)^{2}\right]^{\frac{3}{2}}}
\end{aligned}
$$

Therefore, the elicitation process of Eq. (13) can be shown.

\section{APPENDIX D}

$$
\begin{aligned}
& \frac{d E\left[\pi_{M}\left(u \mid Q_{i}^{*}, t\right)\right]}{d u}(i=1,2) \\
& =R(t) g(u) A(t)+A(t) c_{r}(u) g(u) \\
& -c_{d} A(t) g(u)-c_{n} A(t) g(u)
\end{aligned}
$$

$$
=A(t) g(u)\left\{R(t)+c_{r}(u)-c_{d}-c_{n}\right\}
$$

Therefore, the elicitation process of Eq. (16) can be shown.

\section{APPENDIX E}

$$
\begin{aligned}
& \frac{d E^{1}\left[\pi_{S}(Q, t, u)\right]}{d Q} \\
& =-c_{n}-c_{m}+p \frac{d}{d Q} Q \int_{Q}^{\infty} f(x) d x+p \frac{d}{d Q} \int_{0}^{Q} x f(x) d x \\
& -h_{r} \frac{d}{d Q} \int_{0}^{Q}(Q-x) f(x) d x-s \frac{d}{d Q} \int_{Q}^{\infty}(x-Q) f(x) d x \\
& =-c_{n}-c_{m}+p+s-\left(p+h_{r}+s\right) \int_{0}^{Q} f(x) d x
\end{aligned}
$$

Therefore, the elicitation process of Eq. (18) can be shown.

\section{APPENDIX F}

Eq. (8) can be rewritten as by replacing $w$ in Eq. (7) with $\left(c_{m}+c_{n}\right)$,

$$
\begin{aligned}
E^{2} & {\left[\pi_{s}(Q, t, u)\right]=-t A(t)-c_{t} A(t) } \\
& +\left\{p-\left(c_{m}+c_{n}\right)\right\} Q \\
& -\left(p+h_{r}\right) \frac{\left[\sigma^{2}+(\mu-Q)^{2}\right]^{\frac{1}{2}}-(\mu-Q)}{2} \\
& -S \frac{\left[\sigma^{2}+(Q-\mu)^{2}\right]^{\frac{1}{2}}-(Q-\mu)}{2} \\
& =-t A(t)-c_{t} A(t) \\
& +\frac{1}{2}\left\{2\left\{p-\left(c_{m}+c_{n}\right)\right\} Q-\left(p+h_{r}\right)\left[\sigma^{2}+(\mu-Q)^{2}\right]^{\frac{1}{2}}\right. \\
& \left.+\left(p+h_{r}\right)(\mu-Q)+s(Q-\mu)-s\left[\sigma^{2}+(Q-\mu)^{2}\right]^{\frac{1}{2}}\right\} \\
& =-t A(t)-c_{t} A(t) \\
& +\frac{1}{2}\left\{2\left\{p-\left(c_{m}+c_{n}\right)\right\} Q+\left(p+h_{r}-s\right)(\mu-Q)\right. \\
& \left.-\left(p+h_{r}+s\right)\left[\sigma^{2}+(\mu-Q)^{2}\right]^{\frac{1}{2}}\right\} \\
= & -t A(t)-c_{t} A(t) \\
& +\frac{1}{2}\left\{\left(p+s-h_{r}-2\left(c_{m}+c_{n}\right)\right) Q+\left(p+h_{r}-s\right) \mu\right. \\
& \left.-\left(p+s+h_{r}\right)\left[\sigma^{2}+(Q-\mu)^{2}\right]^{\frac{1}{2}}\right\} .
\end{aligned}
$$


By replacing $w$ in Eq. (12) with $\left(c_{m}+c_{n}\right)$,

$$
\begin{aligned}
& \frac{d E^{2}\left[\pi_{S}(Q, t, u)\right]}{d Q} \\
& =\frac{1}{2}\left\{\left\{p+s-h_{r}-2\left(c_{m}+c_{n}\right)\right\}\right. \\
& \left.-\frac{d}{d Q}\left(p+s+h_{r}\right)\left[\sigma^{2}+(Q-\mu)^{2}\right]^{\frac{1}{2}}\right\} \\
& =\frac{1}{2}\left\{\left\{p+s-h_{r}-2\left(c_{m}+c_{n}\right)\right\}-\left(p+s+h_{r}\right) \frac{(Q-\mu)}{\left[\sigma^{2}+(Q-\mu)^{2}\right]^{\frac{1}{2}}}\right\}
\end{aligned}
$$

Therefore, the elicitation process of Eq. (21) can be shown.

By replacing $w$ in Eq. (13) with $\left(c_{m}+c_{n}\right)$,

$$
\begin{aligned}
& \frac{d^{2} E^{2}\left[\pi_{S}(Q, t, u)\right]}{d Q^{2}} \\
& =\frac{1}{2} \cdot \frac{d}{d Q}\left\{\left\{p+s-h_{r}-2\left(c_{m}+c_{n}\right)\right\}\right.
\end{aligned}
$$

$$
\begin{gathered}
-\left(p+s+h_{r}\right) \frac{(Q-\mu)}{\left[\sigma^{2}+(Q-\mu)^{2}\right]^{\frac{1}{2}}} \\
=-\frac{d}{d Q} \frac{\left(p+s+h_{r}\right)(Q-\mu)}{2\left[\sigma^{2}+(Q-\mu)^{2}\right]^{\frac{1}{2}}} \\
=-\frac{\sigma^{2}\left(p+s+h_{r}\right)}{2\left[\sigma^{2}+(Q-\mu)^{2}\right]^{\frac{3}{2}}}
\end{gathered}
$$

Therefore, the elicitation process of Eq. (22) can be shown.

\section{APPENDIX G}

$$
\begin{aligned}
& \frac{d E\left[\pi_{S}(Q, t, u)\right]}{d u} \\
& \quad=A(t) c_{r}(u) g(u)-c_{d} A(t) g(u)-c_{n} A(t) g(u) \\
& \quad=A(t) g(u)\left\{c_{r}(u)-c_{d}-c_{n}\right\}
\end{aligned}
$$

Therefore, the elicitation process of Eq. (25) can be shown. 